This is the final draft of an article published in the Kant and his German Contemporaries (Cambridge UP, 2018). Please cite the published version, available at https://doi.org/10.1017/9781316493229.002, which differs in the standard ways (formatting, pagination, small grammatical corrections, etc.) from the draft.

\title{
Wolff's Empirical Psychology and the Structure of the Transcendental Logic
}

\section{Brian A. Chance}

While there is a broad consensus that Kant models the structure of the Critique of Pure Reason on aspects of Wolff's system of philosophy, scholars have taken different views about the significance of this fact. When Erik Adickes comments on Kant's ability to "fill old bottles with new wine”, for example, he means to fault Kant for presenting his arguments in a form that is singularly unhelpful for understanding their content. ${ }^{1}$ Adickes' attitude toward the structure of the Critique echoes Schopenhauer's derision decades earlier of Kant's obsession with "systematicity" and has been echoed in the many decades since by scholars on both sides of the Atlantic. ${ }^{2}$ Others, most notably Georgio Tonelli, have argued that one cannot approach the content of the Critique without first understanding its form and that this form is borrowed largely from the conceptual and structure conventions common to the logic books of Kant's contemporaries, a tradition that bears the stamp of Wolff's influence more than that of any other thinker. ${ }^{3}$

With respect to the Transcendental Logic, the standard reading, drawn from Tonelli and endorsed prominently by Paul Guyer and Allen Wood, is that this portion of the Critique "replicates the traditional division of logic textbooks into three sections on concepts, judgments, and inferences". ${ }^{4}$ More specifically, the first and second books of the Transcendental Analytic (the Analytic of Concepts and the Analytic of Principles) are thought to provide the analogue in transcendental logic to traditional accounts of concepts formation and judgments respectively, while the second book of the Transcendental Dialectic (the Dialectical Inferences of Pure Reason) is thought to provide the analogue in transcendental logic to traditional accounts of inference. ${ }^{5}$

While it is undeniable that these parts of the Transcendental Logic contain elements that are similar to the accounts of concept formation, judgment, and inference one finds in the logic books of the Wolffian tradition, it seems to me that these similarities are largely incidental to the structure of the Transcendental Logic. One reason to think this is that the basic structure of this part of the Critique is not governed by the the single tripartite division these scholars reference but by two bipartite divisions, the analytic-dialectic division and the "two books and their various

\footnotetext{
${ }^{1}$ E. Adickes, Kant's Systematik and systembildender Factor (Berlin: Mayer and Müller, 1887 ), 76.

${ }^{2}$ See A. Schopenhauer, The World as Will and Representation, vol. 1 (New York: Dover, 1969), 430-1, 448-9. 469, 470-1, 475, 492, 508, and 514; R. P. Wolff Kant's Theory of Mental Activity (Cambridge, M.A.: Harvard University Press, 1963); 40f. and 81-84; P. Guyer, Kant and the Claims of Knowledge (Cambridge: Cambridge University Press, 1987), 432n1; and G. Dicker Kant's Theory of Knowledge: An Analytical Introduction (Oxford: Oxford University Press, 2004), $94 \mathrm{f}$.

${ }^{3}$ See especially Tonelli's posthumous Kant's 'Critique of Pure Reason' within the tradition of modern logic, ed. D. H. Chandler (Hildesheim et al: Olms, 1994).

4 "Introduction" in Critique of Pure Reason, trans. and ed. P. Guyer and A. Wood (Cambridge: Cambridge University Press, 1998), 3 and 5. See also the introduction to P. Guyer (ed.), Cambridge Companion to Kant's Critique of Pure Reason (Cambridge: Cambridge University Press, 2010), 9-17; R. Brant, Die Urteilstafel: Kritik der reinen Vernunft, A67-76; B92101 (Hamburg: Felix Meiner Verlag, 1991), 7; and E. Conrad, Kants Logikvorlesungen als neuer Schlüssel zur Architektonik der Kritik der reinen Vernunft (Stuttgart-Bad Cannstatt: Frommann-holzboog, 1994), 19 and 75-100.

${ }^{5}$ While almost everything that is true of the discipline of transcendental logic is also true of the portion of the Critique bearing that name, I will for the sake of clarity use "transcendental logic" to denote the former and "Transcendental Logic" to denote the latter.
} 
chapters and sections" that Kant includes as the only subheadings to the Analytic and Dialectic in the original table of contents of the Critique (Axxiii). ${ }^{6}$ Were the tripartite division significant to the structure of the Transcendental Logic, one would expect Kant's presentation of this structure in the table of contents to reflect it. That it does not gives us reason to look for an alternative account. Moreover, given that Wolff does not draw a distinction in kind between what Kant refers to as intuitions, concepts, and ideas, there is as much similarity between the accounts of pure space and time and the ideas of reason in the Aesthetic and Dialectic and the traditional accounts of concept formation as there is between these accounts and the Analytic of Concepts. So one might wonder why the standard reading regards the latter similarity as more significant than the former two.

My goal in this essay is not to directly address concerns that might be raised about the standard reading, however, but to present an alternative and, I believe, more plausible account of Wolff's influence on the structure of the Transcendental Logic, one that focuses more on aspects of his empirical psychology than his logic. In particular, I will argue that the division of the Analytic and Dialectic into "two books and their various chapters and sections" is deeply indebted to a conception of purity that Wolff introduces in his empirical psychology and that this conception sheds more light on the overall structure of the Transcendental Logic than the distinctions Tonelli, Guyer, and Wood emphasize. In section one, I outline two conceptions of purity found in Kant and trace them to similar views in Wolff. In section two, I turn to Kant's views about logic as they are expressed in the Critique and argue that it is best to interpret Kant's taxonomy of logic on its own terms rather than reading it through its terminological similarities to aspects of the Wolffian tradition. In section three, I then argue that the second of the two conceptions of purity identified in section one-which as I will argue in that section, is central to Kant's conception of the pure intuitions of space and time, the categories, and the ideas of reason-is also central to his conception of the structure of the Transcendental Logic. In doing so, I argue against the widespread view that this section of the Critique is modeled solely on what Kant calls pure general logic. ${ }^{7}$ I then conclude by briefly reviewing my account and considering some of its broader implications for our understanding of Kant.

\section{Two Conceptions of Purity in Kant and Wolff}

\footnotetext{
${ }^{6}$ This is in contrast to modern editions, which typically list all the books, chapters, and subheadings for the various parts of the Critique.

${ }^{7}$ It is typically thought that Kant's references to "general logic" in his discussion of transcendental logic are enthymematic references to "pure general logic" and hence that Kant models both the Transcendental logic and transcendental logic on pure general logic and not general logic in its entirety. See Tonelli, Kant's 'Critique of Pure Reason', 61; M. Wolff, Die Vollständigkeit der kantischen Urteilstafel (Frankfurt am Main: Klostermann, 1995), 204; and especially B. Longuenesse, "The Divisions of Transcendental Logic and the Leading Thread" in G. Mohr and M. Willaschek (eds.), Immanuel Kant: Kritik der reinen Vernunft (Berlin: Akademie Verlag, 1998), 135. This view is also implicit in the work of a number of other scholars who have little or nothing to say about the distinction between applied and pure general logic and, hence, effectively treat general logic as if it consisted only in its pure part. See, for example, P. Strawson, Bounds of Sense (London: Methuen, 1966), 75; R. Pippin, Kant's Theory of Form (New Haven: Yale University Press, 1982), 91, and 97-8; K. Mosner, Possibility and Necessity (Washington, D.C.: Catholic University Press, 2008), 34-55 and 56-73; and C. Tolley, "The Generality of Kant's Transcendental Logic," Journal of the History of Philosophy 50 (2012), 417-446, esp. 428.
} 
The most straightforward meaning Kant assigns to "pure" in the first Critique is associated with a priori cognition. In the B Preface, he glosses the "pure part" of a science as "the part in which reason determines its object wholly a priori" (Bx). In this context, the pure part of a science is its a priori part, while the impure part is its a posteriori or empirical part. Similarly, in a passage common to both the A and B Introduction, he writes that "pure reason" is the aspect of reason that "contains the principles for cognizing something absolutely a priori" (A11/B24). And in a prior passage from the $\mathrm{B}$ Introduction, he distinguishes a priori cognition from pure a priori cognition by saying that the former but not the latter may include concepts drawn from experience. As he puts it, what distinguishes pure a priori cognition from merely a priori cognition, is that in the former but not the latter "nothing empirical is intermixed" (B3). ${ }^{8}$

There are passages in the Critique, however, which indicate that Kant recognizes another conception of purity that is not associated with a priori cognition as such but with the ability of one cognitive faculty to create representations without relying on the others. In his provisional formulation of transcendental logic for example, Kant considers the possibility that some concepts relate to objects "not as pure or sensible intuitions but rather merely as acts of pure thinking", emphasizes that such concepts would be "of neither empirical nor aesthetic origin", and characterizes an account of them as part of the "science of pure understanding and of the pure cognition of reason" (A57/B81). Although the concepts in question are what Kant will subsequently call the categories (or pure concepts of the understanding) and these are also a priori and, hence, pure in the sense outlined above, the use of "pure" in these passages does not connote their apriority but rather their independence from intuition and sensibility.

This same conception of purity can also be found in many of Kant's discussions of the pure understanding. In the introduction to the Transcendental Analytic, for example, Kant writes that the "pure understanding separates itself completely not only from everything empirical, but even from all sensibility" (A65/B89, my emphasis). Similarly, he characterizes the task of the Analytic of Concepts as the analysis the understanding whose purpose is to "research the possibility of a priori concepts by seeking them only in the understanding [...] and analyzing its pure use in general" (A66/B91, second emphasis mine). In the opening paragraphs of the Analytic of Concepts, he then returns to this characterization by emphasizing that the categories arise "pure and unmixed from the understanding" (A67/B92). Finally, the task of the Schematism arises from the fact that the "pure concepts of the understanding" are "entirely unhomogeneous" with both empirical and a priori intuition, so if all that were meant by the designation 'pure' was that these concepts are $a$ priori, Kant's statement of this task would make little sense (A137/B176).

As is often the case, traces of both these conceptions can be found the works of Kant's German contemporaries. In particular, the first can be traced to the conception of purity that underlies Wolff s discussion of pure reason, while the second can be traced to the conception of purity that underlies his discussion of the pure understanding. ${ }^{9}$ Since these views receive their most detailed treatment in Wolff's empirical psychology, it is to this portion of his corpus that I now turn.

\footnotetext{
${ }^{8}$ Cf. A50/B74 and A55/B80.

${ }^{9}$ Despite the relevance of these discussions of purity to Kant, very little has been written about them. Indeed, apart from the present discussion and my "Pure Understanding, the Categories, and Kant's Critique of Wolff" in K. Moran (ed.), Freedom and Spontaneity in Kant (Cambridge: Cambridge University Press, forthcoming), the only attempt I am aware of to connect them to Kant is Julius Baumann, Wolffsche Begriffsbestimmungen: Ein Hilfsbüchlein beim Studium Kants (Leipzig: Dürr'schen Buchlandlung, 1910).
} 
In Wolff's Vernünfftige Gedancken von Gott, der Welt und der Seele des Menschen, auch allen Dingen überhaupt or Deutsche Metaphysik, the third chapter of which contains his empirical psychology, he defines reason as the ability to have insight into the "connection of truths" and asserts that one has such an insight when one understands the reason or ground of those truths. ${ }^{10}$ In some cases, it is not possible to attain this insight without appealing to one or more empirical claims or concepts, but in others it is. In these cases, that is, cases in which we have insight "into the connections of things in such a way that one can connect truths with others without assuming any empirical propositions", Wolff says that our reason is pure (lauter). ${ }^{11}$ In his Psychologia empirica, Wolff also explicitly connects pure reason with apriority, asserting that reason is pure (pura) when "in reasoning we do not admit anything except definitions and propositions understood a priori" ${ }^{12}$ Moreover, while Wolff's conception of rational cognition has an obvious affinity with the older, broadly-Aristotelian conception of a priori cognition as "cognition from the ground", his conception of pure rational cognition is more narrow than the former precisely because it does not require empirical claims or concepts and is, thus, also a priori Kant's sense.

In contrast to his discussion of pure reason, Wolff's discussion of the pure understanding emphasizes not the apriority of the understanding's products but rather their independence from our other mental faculties. In the Deutsche Metaphysik, Wolff characterizes the understanding as the "ability to distinctly represent the possible" and distinguishes it from the imagination and reason, both of which represent their objects indistinctly. ${ }^{13}$ Since our representations may involve more than one faculty, however, Wolff also distinguishes between representations that involve the understanding acting on its own and those that involve it acting in consort with other faculties, especially the senses and imagination. In the former cases, our understanding is said to be pure (rein), and in the latter it is said to be impure (unrein). ${ }^{14}$ As Wolff puts it in the Psychologia empirica, the "understanding is pure [purus], if it is free from sense and imagination, and is indeed pure to the extent it is free from sense and imagination" 15

When we consider Kant's discussions of purity in light of this historical background, the comingling of the two conceptions outlined above, at times even in the same passage, makes a good deal of sense. ${ }^{16}$ There are times when it serves Kant's purpose merely to highlight that something is a priori. In the passage from the B Preface, for example, Kant is discussing what makes sciences rational, and his claim is that they are rational only to the extent that they contain a priori cognitions. Similarly, in the first passage from the B Introduction, Kant attempts to clarify his conception of apriority, while in the second, he introduces us to his conception of pure reason. In each of these cases, Kant contrasts a lesser form of a priori cognition with one that is "wholly" (Bx) or "absolutely" (B3 and A11/B24) a priori. At other times, however, Kant needs to highlight that a cognitive faculty that is pure in the first sense is also the sole source of an a priori representation, and in these cases, the connotation of pure shifts subtly to accomplish this purpose. This is the case in Kant's discussion of the categories at A57/B81, A65/B89, A66/B91, A67/B92, and

\footnotetext{
${ }^{10} \mathrm{C}$. Wolff, Vernünfftige Gedancken von Gott, der Welt und der Seele des Menschen, auch allen Dingen überhaupt, $11^{\text {th }}$ edn. (Halle: Regner, 1751[1719]), §381.

${ }^{11}$ Wolff, Deutsche Metaphysik, $\$ 382$.

${ }^{12}$ C. Wolff, Psychologia empirica, $2^{\text {nd }}$ edn. (Frankfurt and Leipzig: Regner, 1738[1732]), §495.

${ }^{13}$ Wolff, Deutsche Metaphysik, $\$ 277$.

${ }^{14}$ Wolff, Psychologia empirica, $\$ 282$.

${ }^{15}$ Wolff, Psychologia empirica, \$314.

${ }^{16}$ See, e.g. A64-5/B89.
} 
A137/B167, but it is also the case in many of his discussions of the a priori intuitions of space and time as well as the ideas of reason since it is important to his overall ambitions in the Critique that these representations are pure in the narrower sense. ${ }^{17}$

\section{Kant's Taxonomy of Logics and the Wolffian Tradition}

Having identified Kant's two conceptions of purity and traced their Wolffian roots, we are now one step closer to identifying the deepest Wolffian influence on the structure of the Transcendental Logic. In particular, I will argue in the next section that transcendental logic is divided into pure and applied parts and that the sense in which the former are pure corresponds to the second of the conceptions of purity I have just outlined. Since Kant introduces transcendental logic as an analogue to what he terms "general logic", however, I must first clarify Kant's own conception of logic and its relationship to the Wolffian tradition. As we will see, while Kant borrows liberally from the terminology of this tradition, the taxonomy he endorses is largely separate from it.

In an approach that one can trace back to Arnould and Nicole's 1662 La Logique ou l'art de penser or Port Royal Logic, Wolff's 1713 Vernünftige Gedanken von den Kräften des menschlichen Verstandes und Ihrem richtigen Gebrauche in Erkänntnis der Wahrheit or Deutsche Logik is divided into accounts of concept formation, judgment, inference, and a discussion on method. In contrast to the Port Royal, however, the Deutsche Logik is not at all neatly divided into these sections but is instead divided into sixteen chapters, the first four of which correspond roughly to the first three parts of the Port Royal and the last twelve of which correspond roughly to its final part on method. In his 1725 condensed presentation of Wolff's system, Ludwig Thümmig labeled the contents of the first four of these sections the "theoretical" part of Wolff's logic and the contents of the last twelve the "practical" part. ${ }^{18}$ Wolff then endorsed this distinction the following year in his Ausführliche Nachricht von seinen eigenen Schrifften, die er in deutscher Sprache heraus gegeben (1726) and applied it retroactively to the chapter divisions of the Deutsche Logik. He then explicitly incorporated the distinction into the structure and table of contents of his Philosophia rationalis, sive Logica (1728), distinguishing between a "Pars I sive Theoretica" and a "Pars II. Practica", after which point the distinction and terminology become the standard if not universally accepted way to divide both the subject of logic and logic textbooks in Germany both in the Wolffian tradition and elsewhere. ${ }^{19}$

\footnotetext{
${ }^{17}$ Aspects of this view are controversial. For a reading of the pure intuitions of space and time as well as the categories that asserts the dependence of each on both the understanding and sensibility, see B. Longuenesse, Kant and the Capacity to Judge (Princeton: Princeton University Press, 1998), 208-9 and 213-6 as well as "Kant on A Priori Concepts: the Metaphysical Deduction of the Categories" in P. Guyer (ed.), Cambridge Companion to Kant and Modern Philosophy (Cambridge: Cambridge University Press, 2006), 129-68 at 151. See also W. Waxman, Kant's Model of the Mind (Oxford: Oxford University Press, 1991), 33-117 and 198 as well as Kant and the Empiricists: Understanding Understanding (Oxford: Oxford University Press, 2005), 28, 69, and 70-75. For an argument against the dependence of the pure intuitions of space and time on the understanding, see J. Messina, "Kant on the Unity of Space and Time and the Synthetic Unity of Apperception," Kant-Studien 105 (2014), 285-304, and for an argument against the dependence of the categories on sensibility, see B. Chance "Pure Understanding".

${ }^{18}$ See L. P. Thümmig, Institutiones philosophiae Wolfianae (Frankfurt and Leipzig: Regner, 1725), §4 and \$51.

${ }^{19}$ G. F. Meiner, Auszug aus der Vernunftlehre (Halle: Johann Justinus Gebauer, 1752), §7 alludes to the distinction but does not incorporate it into the structure of his logic.
} 
Yet while Kant does liken the Critique's Doctrine of Method to practical logic in this sense, his discussion of logic in the "Introduction to the Transcendental Logic" (hereafter Introduction) is not framed in terms of the theoretical-practical distinction. ${ }^{20}$ Moreover, while some of Kant's terminology appears to be drawn from less-orthodox Wolffians, such as Knutzen, Darjes, and Meier, his use of this terminology differs markedly from theirs. Thus, while Knutzen divides his logic into a "general" and "special" part, this division does not correspond to Kant's division between general and special logic, about which I will have more to say in a moment, but to the Wolffian theoretical-practical division. ${ }^{21}$ Similarly, while Darjes and others divide logic into analytical and dialectical parts, Kant rejects Darjes' identification of the dialectic part of logic with probability. ${ }^{22}$ Finally, while Meier's way of drawing the Wolffian distinction between theoretical and practical logic has a certain affinity with Kant's division of general logic into pure and applied parts, Kant also goes to great lengths to distinguish what he calls applied logic from the practical logic of "the schools" (A708/B736). Indeed, the only unambiguous way Kant follows the tradition is in his insistence that logic is the science of the rules for the correct use of the understanding. Yet even here Kant's agreement is in part only nominal since in his discussions of logic Wolff frequently uses "understanding" in a broad sense that includes our sensible faculties, which Kant's conception of logic explicitly excludes. ${ }^{23}$

Instead of trying to align Kant's discussion of logic with the Wolffian tradition, then, I believe it is best to treat the taxonomy he outlines in the Introduction as sui generis. In the first section of the Introduction, Kant defines logic as the "science of the rules of the understanding in general" and distinguishes between two "aims" with which this science can be undertaken (A52/B76). The first is with the aim of examining the general use of the understanding and constitutes general logic which "contains the absolutely necessary rules of the understanding, without which no use of the understanding takes place" and "concerns these rules without regard to the different objects to which it [i.e. the understanding] may be directed"(ibid). The second is with the aim of examining the rules for the use of the understanding when it is applied to a particular kind of object and is called a special logic.

Although Tonelli has argued that the entire Critique should be regarded as a special logic for metaphysics, Kant appears introduce the notion of a special logic only to set it aside. ${ }^{24}$ The term does not appear again in the Critique, and while one might be tempted to regard Kant's discussion of the mathematical method in the Discipline of Pure Reason as an instance of a special logic (in this case one for mathematics), Kant's larger aim in that section is not to revisit this species of logic but to establish a set of rules for the use of pure reason designed to mitigate or eliminate the deception associated with transcendental illusion. ${ }^{25}$

In contrast, Kant does mention general logic again in several parts of the Critique, always in an attempt to explain some aspect of transcendental logic; and in the Introduction, he further

\footnotetext{
${ }^{20}$ Cf. A708/B736.

${ }^{21}$ M. Knutzen Elementa philosophiae rationalis seu logicae (Königsberg and Leipzig: Hartung, 1747), 45.

22 See G. Tonelli, “Der historische Ursprung der kantischen Termini 'Analytik' und 'Dialektik'”, Archiv für Begriffsgeschichte 7 (1962), 120-139. Meier, Auszug, §6 also alludes to this distinction.

${ }^{23}$ See, e.g. Wolff, Deutsche Logik, "Vorbericht von der Weltweisheit", §10 and Deutsche Logik, Ch.1, §15.

${ }^{24}$ See Tonelli, Kant's 'Critique of Pure Reason', 81. Cf. Wolff, Vollständigkeit, 204. For criticism, see Tolley, "Generality”, $422-425$.

${ }^{25}$ Thanks to Desmond Hogan for raising this concern. See B. Chance, "Kant and the Discipline of Reason”, European Journal of Philosophy 23 (2013), 87-110 for a detailed reading of the Discipline along the lines indicated here.
} 
divides general logic into pure and applied parts. The former is an entirely a priori science that "abstracts from all empirical conditions under which our understanding is exercised", while the latter is an a posteriori science that concerns the rules for the use of the understanding "under the subjective empirical conditions that psychology teaches" (A53/B77). Among these conditions are "the influence of the senses, [...] play of imagination, laws of memory, the power of habit, inclination and [...] the sources of prejudice" (ibid). Subsequently, Kant writes that applied general logic is a "representation of the understanding and the rules for its necessary use in concreto, namely under the contingent conditions of the subject, which can hinder or promote this use, and which can all be given only empirically" (A54/B79). Such a representation, Kant continues:

[...] deals with attention, its hindrance and consequences, the cause of error, the condition of doubt, of reservation, of conviction, etc., and general and pure logic is related to it as pure morality, which contains merely the necessary moral laws of a free will in general, is related to the doctrine of virtue proper, which assesses these laws under the hindrances of the feelings, inclinations, and passions to which human beings are more or less subject, and which can never yield a true and proven science, since it requires empirical and psychological principles just as much as that applied logic does. (ibid)

The analogy Kant draws in this passage between pure and applied logic on the one hand and pure morality and the doctrine of virtue on the other in instructive. Just as there is one normative law to which the wills of all rational beings are subject (i.e. the moral law), there is also one normative law (or set of laws) to which all use of the understanding is subject. Further, just as there are various ways in which the contingent features of rational beings help or hinder the complete determination of their wills by the moral law and, hence, their use of the will in accordance with its supreme rule, there are also ways in which these features may help or hinder the determination of the understanding in accordance with the rules of pure general logic and, hence, help or hinder our use of the understanding in accordance with the rules that govern it. Finally, just as there will be as many doctrines of virtue-in the sense Kant uses the term here-as there are kinds of rational beings whose wills are subject to different "empirical and psychological principles", there will also be as many applied general logics as there are different "contingent conditions of the subject" or, what is perhaps a better way to put it, as there are subjects with different contingent conditions (ibid). Thus, applied general logic can be described as an attempt to tailor the rules of pure general logic to different rational beings or kinds of rational beings, each of which has the same faculty of the understanding but each of which must also exercise this faculty under different empirical conditions.

Despite some obvious similarities between Kant's applied general logic and Wolffian practical logic, including the fact that "applied" is a term Kant sometimes uses to describe the latter, Kant presents them as distinct. Thus, in a parenthetical comment inserted before his description of applied logic at A54/B78, he contrasts his understanding of applied general logic with "the common signification of this word, according to which it ought to contain certain exercises [Exerzitien] to which pure logic gives the rule" (ibid). The word whose "common signification" Kant alludes to is "applied" (angewandt), and the "exercises" in question are specific applications (Anwendungen) of the accounts of concept formation, judgment, and inference presented in theoretical logic, such as the discovery of new truths or the presentation to others of views one believes to be true. Importantly, however, this task is distinct from the presentation of 
the highly general yet still empirically conditioned ways in which features of human psychology help and hinder our ability to adhere to the necessary conditions for the correct use of the understanding laid out in pure general logic. While practical logic teaches us how to use the account of the syllogism to produce actual demonstrations (i.e. chains of syllogisms beginning from or reduced to first principles) of claims, for example, applied general logic might focus on the ways in which a person's discernment or attentiveness affects her ability to correctly apply these rules. The former is the application of a logical rule to a specific instance, while the latter is the process of adapting universally valid logical rules to a certain kind of thinker.

In the second section of the Introduction, the section entitled "On transcendental logic", Kant then proceeds to introduce transcendental logic by way of contrast with general logic. That is, Kant proceeds to introduce his reader to the hitherto unknown discipline of transcendental logic by suggesting that it will be like the discipline of general logic, the outlines of which he has given in section one. "General logic," Kant writes, "abstracts [...] from all content of cognition", which is to say that it abstracts from "any relation of [of cognition] to the object", and "considers only the logical form in the relation of cognitions to one another", which form Kant glosses as the "form of thinking in general" (A55/B79). Since the Transcendental Aesthetic has shown us that there are both pure and empirical intuitions of objects (i.e. the pure forms of space and time and the mathematical objects constructible by means of those forms on the one hand and those same forms imbued with the "matter" of sensation on the other), it is now possible to distinguish between a "pure and empirical thinking of objects" (A55/B80, my emphasis). This latter distinction allows us to conceive of a new kind of logic, i.e. a new set of rules for the use of the understanding, that does not abstract from all the content of cognition as general logic does but rather abstracts merely from all the empirical content of cognition, leaving behind the pure content the existence of which was established in the Aesthetic. Such a logic, that is, a set of rules for the use of the understanding with respect to the pure content of cognition, is the discipline Kant introduces as transcendental logic (Cf. A57/B81).

\section{General Logic (Pure and Applied) and Transcendental Logic}

It is often thought that the references Kant makes to "general logic" in section two of the Introduction (two in the first paragraph and one in the last) are in fact references to pure general logic. ${ }^{26}$ Moreover, since Kant's characterization of pure logic does little to distinguish it from the theoretical logic of the Wolffian tradition, this reading serves to strengthen the view of Adickes, Tonelli, Guyer, Wood, and others that the Transcendental Logic borrows its structure largely from the logics of Kant's German contemporaries. The justification for this reading seems to be that since applied general logic is a posteriori and transcendental logic is a priori, there can be nothing in applied general logic to which anything in transcendental logic is analogous; and if it is not general logic in toto to which Kant is referring in these passages, as the previous observation would seem to indicate, the only reasonable conclusion is that he is referring merely to pure general logic. ${ }^{27}$

On its face, however, this suggestion is puzzling. In the first place, Kant does not provide the least indication at any point in the Introduction that he intends to use "general logic" as an

\footnotetext{
${ }^{26}$ See the literature cited in footnote 7.

27 This is essentially Longuenesse's objection in "Divisions of Transcendental Logic", 135.
} 
abbreviation for "pure general logic". It is true, of course, that he claims only the pure part of general logic is "properly science", but he does so in the context of also reaffirming that general logic has both pure and applied parts (A53/B78). Moreover, he concludes the first section of the Introduction, the section titled "On logic in general", with the long description of applied general logic from which I quoted a few paragraphs back. In the longer paragraph from which this description is drawn, Kant's sole concern is to elaborate on his conception of applied general logic; and this paragraph is meant to complement the elaboration of his conception of pure general logic contained in the immediately preceding paragraph. Thus, Kant spends two long paragraphs of "On logic in general", nearly one third of the total section, elaborating on the parts of general logic; and he places this discussion immediately before his comparison of general logic with transcendental logic at the start of the next section. Further, there is no indication that Kant discusses applied general logic in order to set it aside. Quite the contrary, the fact that Kant discusses it in the depth he does indicates that it will be relevant to the discussion of transcendental logic that immediately follows. ${ }^{28}$

In addition to the textual evidence in favor taking Kant at his word when he draws an analogy between general logic in its entirety and transcendental logic, it is also important to note that the primary argument against doing so is deeply flawed. To see why this is so, consider first that the juridical deductions of the Holy Roman Empire were empirical and that Kant nevertheless chose them as the model for the (clearly a priori) Transcendental Deduction. ${ }^{29}$ The reason their empirical status did not prevent him from doing so, of course, is that two things can be analogous in some respects without being analogous in all respects. Indeed, this is especially true on Kant's somewhat idiosyncratic account of analogy according to which an analogy does not signify "an imperfect similarity between two things, but rather a perfect similarity between two relations in wholly dissimilar things" (Pro, 4:358; cf. A180/B222). To say that A is analogous to B is thus to say that there is some $\mathrm{C}$ that stands in relation to $\mathrm{A}$ and some $\mathrm{D}$ that stands in relation so $\mathrm{B}$ and that there is a "perfect similarity" between the relation in which A stands to C and the relation in which B stands to D. It is beyond doubt that Kant introduces transcendental logic as a field of inquiry that is analogous to something he calls "general logic", but the fact that general logic has both an a priori and an empirical part does not entail that transcendental logic can be analogous to general logic only if it too has an a priori and empirical part. Rather, all that is needed to justify Kant's analogy is the existence of elements in transcendental logic that stand in the same relationship to each other as pure general logic stands to applied general logic. And since applied general logic concerns the ways in which cognitive elements extraneous to the understanding affect the use of the understanding prescribed in pure general logic, the fact that applied general logic is empirical would only preclude the existence of such elements if the only relevant relation between pure and applied general logic were the apriori-empirical one.

As we have seen, of course, Kant operates with two different conceptions of purity in the Critique, the second of which is distinct from the apriori-empirical relation. In particular, as we saw in section two, it is important to Kant's conception of the pure intuitions of space and time, the pure concepts of the understandings, and the ideas of reason that they are pure not only in the sense of being a priori representations but also in these sense of being products of a single mental

\footnotetext{
${ }^{28}$ Cf. G, 4:410n and JL, 9:18.

${ }^{29}$ See D. Henrich, "Kant's Notion of a Deduction and the Methodological Background of the First Critique" in E. Förster (ed.), Kant's Transcendental Deductions (Stanford: Stanford University Press, 1988) 29-46.
} 
faculty. Moreover, pure general logic is also pure in both these senses. That is, it is both an a priori science and one that describes the capacities of the understanding irrespective of its interaction with other mental faculties. As a result, one can identify at least two relations between pure and applied general logic that could serve as the basis for an analogy between general logic and transcendental logic. The first is the apriori-empirical relation, and the second is the relationship between the activity of the understanding on its own and its activity in conjunction with our other mental faculties.

It is with respect to this latter relation that I suggest there is a "prefect similarity" between the relationship in which pure general logic stands to applied general logic and the relationship in which certain portions of the Transcendental Logic stand to others. In particular, I suggest that the first books of the Transcendental Analytic and Transcendental Dialectic constitute the pure parts of transcendental logic, while their second books constitute its applied parts. That is, the first book of each part of the Transcendental Logic addresses the contribution of its respective faculty to synthetic a priori cognition, genuine in the case of the Analytic and spurious in the case of the Dialectic, while the second book of each part addresses the interaction of this faculty with other cognitive faculties, which interaction is a further part of the production of synthetic a priori cognition, again genuine in the case of the Analytic and spurious in the case of the Dialectic.

More specifically, the task of the Analytic of Concepts is to show, first, in the Metaphysical Deduction that there are pure concepts of the understanding and, second, in the Transcendental Deduction (a) that these concepts have "objective validity" and (b) that they have such validity always and only when applied to objects of sensible intuition, while the task of the Analytic of Principles is to provide an account of the specific ways in which these concepts apply to such objects. ${ }^{30}$ This account is carried out over the course of the three chapters of the Analytic of Principles. In the first of these chapters, the "Schematism of Pure Concepts of the Understanding", Kant provides a spatio-temporal interpretation of each of the twelve pure concepts of the understanding, showing what results when these concepts are applied to the subjective but in contrast to general applied logic a priori "conditions under which our understanding is exercised" (A53/B77). In the second, the "System of Principles of Pure Understanding", Kant then shows how each of these schematized concepts yields a synthetic a priori principle that governs the way objects of sensible intuition can appear to us, and in the third, "On the Ground of the Distinction of all Objects in general into Phenomena and Noumena", Kant summarizes the results of the previous two chapters and introduces the notion of a noumenon and, in the B-edition, the distinction between a noumenon in the positive sense and a noumenon in the negative sense as a boundary concept or Grenzbegriff in order to completely delineate the sphere of understanding's proper use.

\footnotetext{
${ }^{30}$ Guyer develops this sort of reading of the division of labor between the two books of the Analytic in "Space, Time, and the Categories" in Ralph Schumacher et al. (eds.), Idealismus als Theorie der Repräsentation (Berlin: Mentis, 2001), 313-338. It might be objected that the way I have characterized Transcendental Deduction actually shows it to be part of applied general logic, as I am conceiving it, since it is beyond doubt that the Deduction concerns itself with the cooperation of the pure understanding with sensibility and imagination. In reply, I suggest that one way of understanding the project of the Transcendental Deduction is as an attempt to establish the possibility of applied transcendental logic as I have presented it. For what is at issue in the Deduction is whether the pure concepts of the understanding can be applied to the material given in pure intuition to produce the cognition of an object, and this is a question that must be resolved before one can address the more specific question of how the understanding cooperates with sensibility and imagination in this way.
} 
Similarly, the first book of the Dialectic, "On the Concepts of Pure Reason", provides an account of the way in which the activity of reason gives rise to a unique set of mental representations, the so-called ideas of reason (the soul, world-whole, and God), and is meant to parallel the account provided in the first book of the Analytic of the way in which the activity of the understanding gives rise to a set of representations unique to it, i.e. the pure concepts of the understanding (or categories). ${ }^{31}$ For its part, second book of the Dialectic, "The Dialectal Inferences of Pure Reason", describes not the use of these representations, as did second book of the Analytic with respect to the categories, but rather the misuse of these representations that arises from their combination with those of the understanding, sensibility, or both. In particular, the "Paralogisms of pure reason" describe the misuse of the categories that arises when they are applied to the a priori representation of the "I think"; the "Antinomy of Pure Reason" describe the misuse of the categories that arises when they are applied to "absolute totality in the synthesis of appearances" (A407/B434); and the "Ideal of Pure reason" describes the misuse of the categories that arises then they are applied to the a priori idea of the ens realissimum.

As for the appendices to the Analytic and Dialectic ("On the Amphiboly of Concepts of Reflection" and "Appendix to the Transcendental Dialectic"), each falls clearly on the applied side of transcendental logic. Each of course is separated from Kant's central discussion of applied transcendental logic in its respective section of the Critique; however, this is simply because neither fits well into the general division of transcendental logic into an analytic and dialectic. In particular, while the analytic part of transcendental logic focuses on the use of the understanding in the cognition of truth, the Amphiboly does not address the ways in which the pure understanding cooperates with other pure faculties to produce truth but instead the ways in which it and sensibility are misapplied to produce error. Similarly, while the dialectical part of transcendental logic concerns error, the Appendix does not address the ways in which the ideas of reason are misapplied to produce error but the ways in which their regulative use may guide us to new truths.

Once we are primed to read the Transcendental Logic in this way, additional evidence comes into view. In particular, if one follows Kant's use of "applied" and its cognates, it becomes clear that he signals many of the divisions I have mentioned. In "On transcendental logic", for example, he comments that a cognition is only properly termed transcendental when it is one "by means of which we cognize that and how certain representations (intuitions or concepts) are applied entirely a priori, or are possible" (A56/B80). If we relate this passage to the content of the Transcendental Logic, it is easy to see Kant presenting in miniature the basic divisions of the Analytic I have just sketched. The Metaphysical Deduction establishes "that and how" the pure concepts of the understanding "are possible", while the Transcendental Deduction establishes that these concepts can be "applied a priori" and the Analytic of Principles establishes how this application is possible. Similarly, in the introduction to the Analytic of Principles-the introduction to what I am calling the applied part of the Transcendental Analytic-Kant emphasizes that, in contrast to general logic, transcendental logic does not merely give the rule for the power of judgment to follow but is also able to "indicate a priori the case to which the rules ought to apply" (A135/B175).

Given that Kant also tends to use "use" (Gebrauch) and its cognates in a way that suggests it has broadly the same connotation as "application", we can identify additional passages of the

${ }^{31}$ On this parallel, see A321/B378. 
Critique that signpost the divisions I have outlined. In the continuation of the passage at A135/B175, for example, Kant glosses the task of the Schematism as dealing with "the sensible conditions under which pure concepts can be employed [gebraucht]", but in the passages of the Schematism that immediately follow, he consistently discusses the "application" of the categories (A136/B175; cf. A137-40/B176-9). Similarly, in the final sentence of the B-Deduction, Kant announces that he will discontinue his practice of numbering the sections of the Critique because he has reached the end of his discussion of "elementary concepts" and is turning in the second book of the Analytic to the representation of their "use" (B168). Thus, in addition to capturing the conceptual divisions between the various parts of the Transcendental Logic in an especially clear way, the account of the Transcendental Logic's structure I have presented is also supported by many of Kant's programmatic statements in this part of the Critique.

\section{Conclusion}

In this essay, I have argued that the deepest Wolffian influence on the structure of the Transcendental Logic is not from Wolff s works on logic, as commentators from Adickes to Guyer and Wood have tended to think, but from his empirical psychology. Specifically, I have argued that Kant recognizes not one but two conceptions of purity, both of which can be traced to Wolff and that the second of these conceptions, according to which a representation is pure just in case it is the product of a single mental faculty, is central to both Kant's conception of transcendental logic and the structure of the Transcendental Logic. As Kant emphasizes in the Critique's original table of contents, the Transcendental Logic is divided into the Transcendental Analytic and Transcendental Dialectic, each of which is further divided into "two books and their various chapters and sections" (Axxiii). On my account, the first of these books constitutes the pure part of its respective division, while the second constitutes the applied part. Both of these parts are pure in the first sense Kant recognizes-they are a priori-but since it is clear from the outset that Kant conceives of transcendental logic as an a priori discipline, it is only the second conception of purity that allows us to properly distinguish the various parts of transcendental logic and, by extension, the Transcendental Logic.

That the proper division of transcendental logic has gone unrecognized for more than two centuries is due primarily to two factors. The first is the dismissive attitude that interpreters of Kant from Schopenhauer to the present have taken toward the relationship between the form and content of the Critique, and the second is an overemphasis on what I have suggested are largely superficial similarities between transcendental logic and the logics of Kant's predecessors. In particular, while parts of transcendental logic are similar to the accounts of concept formation, judgment, and inference found in these logics, I have argued that these similarities do not pick out the most significant conceptual divisions of transcendental logic or the most important structural divisions of the Transcendental Logic.

In addition to its overall coherence, one advantage of this reading is that it provides a ready explanation for an otherwise puzzling feature of the Transcendental Logic, namely that it devotes so much space to sensibility and imagination. On its face, this feature is in tension with the assumption that Kant models the Transcendental Logic on the logics of the Wolffian tradition since apart from referencing the senses as a source for the content of concepts, these logics have very little to say about the senses or sensibility and even less so say about the imagination. 
Moreover, even if we assume, as I have argued we should, that Kant presents general logic as a largely sui generis discipline, the extensive discussions of sensibility and imagination in the Transcendental Logic make it remarkably unlike the pure part of general logic, which as we have seen is what most commentators have mistakenly believed is the model for Transcendental Logic.

One recent attempt to address this problem has been to claim that, despite appearances, the Analytic of Principles and the entire Transcendental Dialectic are not part of the discipline of transcendental logic at all but rather a "special logic for thought about objects of experience". 32 Since this reading involves attributing to Kant the view that the vast majority of the material addressed in the portion of the Critique called Transcendental Logic is not in fact part of the discipline of transcendental logic, I believe we should resist it. Fortunately, the assumption that the Transcendental Logic recapitulates the structure of general logic in both its pure and applied parts provides us with a straightforward explanation for the importance of sensibility and imagination in these sections of the Critique, namely that, as the applied parts of general logic, their purpose is to elaborate on the ways in which the understanding operates in conjunction with other cognitive faculties to produce genuine synthetic a priori cognition in the case of the Analytic and putative synthetic a priori cognition in the case of the Dialectic.

More broadly, the fact that a conceptual distinction introduced within Wolff's empirical psychology turns out to be central to Kant's conception of transcendental logic suggests that more attention should be paid to the relationship between Wolffian psychology and the Critique. Falk Wunderlich has recently drawn attention to the relevance of Wolffian psychology to the project of the Transcendental Deduction. ${ }^{33}$ However, the argument of this essay suggests the need for a broader examination of Wolffian psychology project of the Transcendental Logic as a whole. Kant's reliance on the second of Wolff's conceptions of purity in this part of the Critique also naturally raises the question of whether his conceptual debt to Wolff extends beyond the Transcendental Logic to other parts of the Critique. Finally, given the many contexts in which the notion of purity plays a central role in Kant's philosophy, it is natural to ask whether the Wolffian views I have identified can shed light on his philosophy more generally.

A detailed examination of these issues lies beyond the scope of this essay. Yet it is a measure of the importance of reading Kant not merely against the background of Descartes, Spinoza, Leibniz, Locke, Hume, and Berkeley but also of his German contemporaries that an examination of Wolff's influence on the structure of the Transcendental Logic allows us to raise them. ${ }^{34}$

\footnotetext{
32 Tolley, "Generality”, 443. Cf. 444n60.

${ }^{33}$ See F. Wunderlich, Kant und die Bewußtseinstheorien des 18. Jahrhunderts (Berlin: De Gruyter, 2005).

${ }^{34}$ I am grateful to Lawrence Pasternack, the editors, and audiences at Western University and the 2015 Southern Study Group of the North American Kant Society for comments on previous versions of this paper.
} 